\title{
Reduction of miR-21 induces glioma cell apoptosis via activating caspase 9 and 3
}

\author{
XUAN ZHOU ${ }^{1,2^{*}}$, JUNXIA ZHANG ${ }^{1,3^{*}}$, QIANG JIA ${ }^{4}$, YU REN5, YINGYI WANG ${ }^{3}$, LEI SHI ${ }^{6}$, \\ NING LIU ${ }^{3}$, GUANGXIU WANG ${ }^{1}$, PEIYU PU ${ }^{1}$, YONGPING YOU ${ }^{3}$ and CHUNSHENG KANG ${ }^{1}$ \\ ${ }^{1}$ Department of Neurosurgery, Tianjin Medical University General Hospital, Laboratory of Neuro-Oncology, Tianjin \\ Neurological Institute, Tianjin 300052; ${ }^{2}$ Department of Head and Neck Cancer, Tianjin Medical University \\ Cancer Institute and Hospital, Tianjin 300060; ${ }^{3}$ Department of Neurosurgery, The First Affiliated Hospital \\ of Nanjing Medical University, Nanjing 210029; ${ }^{4}$ Department of Neurosurgery and Gamma Knife \\ Center, Tianjin Medical University 2nd Hospital, Tianjin 300211; ${ }^{5}$ Tianjin Research Center of Basic \\ Medical Science, Tianjin Medical University, Tianjin 300070; ${ }^{6}$ Department of Neurosurgery, The \\ First People's Hospital of Kunshan affiliated with Jiangsu University, Suzhou 215300, P.R. China
}

Received February 26, 2010; Accepted April 29, 2010

DOI: $10.3892 /$ or_00000846

\begin{abstract}
Extensive data indicate that miR-21 plays a critical role in gliomagenesis, however, knowledge is limited on the mechanism of action of miR-21, including cell proliferation, apoptosis, and migration. In this study, we showed that down-regulation of miR-21 expression by antisense oligonucleotides inhibited glioma cell proliferation and induced cell apoptosis. Moreover, reduction of miR-21 activated caspase 9 and 3 , which may be mediated by modulating multiple potential target genes, such as TIMP3. Together, these findings indicate that miR-21 plays a key role in regulating cell apoptosis in gliomas and may serve as a target for effective therapies.
\end{abstract}

\section{Introduction}

MicroRNAs (miRNAs) are a new class of small, non-coding RNAs and provide important regulatory functions at posttranscriptional level by induction mRNA degradation or

Correspondence to: Dr Chunsheng Kang, Department of Neurosurgery, Tianjin Medical University General Hospital and Laboratory of Neuro-Oncology, Tianjin Neurological Institute, Tianjin 300052, P.R. China

E-mail: kang97061@yahoo.com

Dr Yongping You, Department of Neurosurgery, The First Affiliated Hospital of Nanjing Medical University, Nanjing 210029, P.R. China E-mail: yyp19@njmu.edu.cn

${ }^{*}$ Contributed equally

Key words: glioma, miR-21, apoptosis, caspase inhibition of translation. MiRNA aberrant expression profile is a notable molecular label to human cancers $(1,2)$. These are roughly divided into two groups, those miRNAs that are up-regulated or amplified in cancer and likely to be acting as oncogenes, and those miRNAs deleted or down-regulated in cancer appear to be acting as tumor suppressors (3).

MiR-21 is located in 17q23.2 and conversed in vertebrates including humans. MiR-21 was validated to be overexpressed in breast, colon, lung and head and neck cancer. The group of Farace proved that miR-21 was the most up-regulated miRNA in GBM tissues compared to the relative resection margin brain tissues (4). Previously, we profiled miRNA expression in five glioblastoma cell lines (U251, TJ866, TJ905, TJ899 and A172) and human astrocytoma cell line (H4), and found that miR-21 exhibited the most significant increase relative to normal brain tissue (5). It has been reported that miR-21 plays critical roles in regulating glioma malignant phenotype. MiR-21 contributes to glioma invasiveness by down-regulation of MMP inhibitors (RECK and TIMP3), which lead to activation of MMPs (6). Suppression of miR-21 leads to enhanced cytotoxicities of VM-26 against glioma cells by target gene LRRFIP1, whose product is an inhibitor of NF- $\mathrm{KB}$ signaling (7). In addition, in glioblastoma cell line T98G, inhibition of miR-21 increases endogenous levels of PDCD4, an important tumor suppressor gene, and overexpression of miR-21 inhibits PDCD4-dependent apoptosis (8). Additionally, our recent data showed that reduction of AKT by AKT siRNA decreased miR-21 expression in glioma cells (9). However, little direct evidence exists to show the mechanism of miR-21 involved in gliomagenesis.

In the present study, we identified that reduction of miR-21 by antisense oligonucleotides inhibited glioma cell proliferation and induced cell apoptosis. Moreover, downregulation of miR-21 expression activated the caspase 9 and 3 pathway possibly by regulation of multiple target gene expression. These results indicate that miR-21 is an important oncogene that leads to caspase 9 and 3 mediated mitochondrial apoptosis in glioma cells. 


\section{Materials and methods}

Cell culture and oligonucleotide transfection. Human U87 glioma cell lines were purchased from Chinese Academy of Sciences Cell Bank. U87 cells were maintained in a $37^{\circ} \mathrm{C}$, $5 \% \mathrm{CO}_{2}$ incubator in DMEM supplemented with $10 \%$ fetal bovine serum (FBS). 2'-O-methyl (OMe)-oligonucleotides were chemically synthesized and purified by GenePharma Co., Ltd. (Shanghai, China). Sequences were: anti-miR-21 (As-miR-21), 5'-UCAACAUCAGUCUGAUAAGCUA-3'; miRNA scrambled (negative control), 5'-UUGUACUAC ACAAAAGUACUG-3'. Cells were transfected using Lipofectamine 2000 (Invitrogen, USA) at 70-90\% confluency, and transfected again $24 \mathrm{~h}$ later. Twenty-four hours after transfection, cells were harvestd for further studies.

MiR-21 RT real-time PCR. TRIzol reagent was used to isolate total RNA from U87 cells $24 \mathrm{~h}$ after transfection. The RT real-time PCR was carried out with the miRNA detection kit (Ambion, USA). Amplification reaction protocol was performed for 40 cycles consisting $95^{\circ} \mathrm{C}$ for $3 \mathrm{~min}, 95^{\circ} \mathrm{C}$ for $15 \mathrm{sec}, 60^{\circ} \mathrm{C}$ for $30 \mathrm{sec}$. Both RT and PCR primer were purchased from Ambion. 5S RNA was used for normalization. Relative quantification was conducted using amplification efficiencies derived from cDNA standard curves and relative gene expression obtained. Data are shown as fold change $\left(2^{-\Delta \Delta C t}\right)$ and analyzed initially using Opticon monitor analysis software V2.02 (MJ Research, USA).

Cell growth assays. Cells were plated at $10^{4}$ cells per well in 96-well plates with six replicate wells for each condition, transfected with oligonucleotides, and assayed 24 and $48 \mathrm{~h}$ after transfection. MTT (20 $\mu \mathrm{l})(5 \mathrm{~g} / \mathrm{l}$, Sigma, USA) was added into each well at each day of consecutive 6 days after treatment and the cells were incubated for additional $4 \mathrm{~h}$, the supernatant was then discarded. DMSO $(200 \mu 1)$ was added to each well to dissolve the precipitate. Optical density (OD) was measured at wavelength of $550 \mathrm{~nm}$. All data points represent the mean of a minimum of six wells. Cell growth inhibition formula is (AC-AT)/AC x $100 \%$ (AC, absorbance value of the blank control group; AT, absorbance value of the experimental group).

Apoptosis assays. Cells were plated in 12-well plates and transfected with oligonucleotides. The apoptosis ratio was analyzed $24 \mathrm{~h}$ after transfection via using AnnexinV FITC apoptosis detection kit (BD Biosciences, USA) according to the manufacturer's instructions. Annexin V FITC and propidium iodide (PI) double stain was used to evaluate the percentages of apoptosis. Annexin $\mathrm{V}^{-}$and $\mathrm{PI}^{-}$cells were used as controls. Annexin $\mathrm{V}^{+}$and $\mathrm{PI}^{-}$cells were designated as apoptotic and Annexin $\mathrm{V}^{+}$and $\mathrm{PI}^{+}$cells displayed necrotic. Tests were repeated in triplicate.

Detection of caspase 3 activation. Cells were plated in 96-well plates, transfected as described above and analyzed 24 and $48 \mathrm{~h}$ after transfection using the caspase 3 colormetric assay kit (Alexis Biochemicals, USA) according to the manufacturer's instructions. Samples were read after $1 \mathrm{~h}$ of incubation with the caspase substrate on a microtiter plate reader at $400 \mathrm{~nm}$. Tests were repeated in triplicate.

Western blot analysis. Equal amounts of protein per lane were separated by $8 \%$ SDS-polyacrylamide gel and transferred to PVDF membrane. The membrane was blocked in 5\% skim milk for $1 \mathrm{~h}$ and then incubated with a specific antibody for $2 \mathrm{~h}$. The antibodies used in this study were: antibodies to caspase 3, caspase 9 and PTEN (Santa Cruz, USA), TIMP3 (Zhongshan, China). The antibody against $\beta$-actin (Santa Cruz) was used as control. The specific protein was detected by using a SuperSignal protein detection kit (Pierce, USA). The band density of specific proteins was quantified after normalization with the density of $\beta$-actin.

Xenograft tumor assay. BALB/c-A nude mice at 6 weeks of age were purchased from animal center of the Cancer Institute of Chinese Academy of Medical Science. Glioma subcutaneous model was established as previously described (10). When the subcutaneous tumor reached $200 \mathrm{~mm}^{3}$ in size, 30 mice were randomly divided into 3 groups. A mixture of $10 \mu 1$ Lipofectamine 2000 and $10 \mu \mathrm{g}$ oligonucleotides was injected into the xenograft tumor model in a multi-site injection manner. Mice in the blank control group received $10 \mu \mathrm{l}$ of PBS only. Treatment was conducted every 3 days. The tumor volume was measured with a caliper every 3 days, using the formula volume $=$ length $\mathrm{x}$ width ${ }^{2} / 2$ (11). At the end of 18-day observation period, the mice bearing xenograft tumors were sacrificed and the tumor tissues were removed for formalin fixation and preparation of paraffin-embedded sections.

In situ hybridization and TUNEL analysis. For detecting miR-21 expression and apoptotic cells simultaneously, in situ hybridization was performed and then apoptosis was detected by TUNEL method. Using antisense locked nucleic acid (LNA) modified oligonucleotides probe, in situ hybridization was performed with In-situ hybridization kit (Boster, China). LNA/ DNA oligos contained locked nucleic acids at eight consecutive centrally located bases (indicated by underline) and had the following sequences: LNA-miR-21 5'-TCA ACA TCA GTC TGA TAA GCT A-3'. Sections were deparaffinized and deproteinated, and then prehybridized for $2 \mathrm{~h}$ in hybridization liquid in a humidified chamber. Sections were incubated with $20 \mu 1$ LNA-miR-21 hybridization solution at $42^{\circ} \mathrm{C}$ for $16 \mathrm{~h}$, and $\mathrm{Cy} 3$-avidin was used to label miR-21 at a concentration of $0.5 \mathrm{mg} / \mathrm{ml}$. Then the apoptotic cell death was examined by TUNEL method using an In-situ cell death kit (Roche, USA) according to the manufacturer's instructions. Nuclei were counterstained with DAPI karyotyping kit (Genmed, USA). Positive cells were visualized by FluoView confocal laser scanning microscopes, FV1000 (Olympus, Japan) and analyzed by IPP5.1 (Olympus).

Immunohistochemistry assay. Sections were used for examination of caspase 3, caspase 9, PTEN and TIMP3 expression in the tumors. For the immunohistochemistry study, sections were incubated with appropriate primary antibody (1:200 dilution) overnight at $4^{\circ} \mathrm{C}$. Biotinylated secondary antibody (1:200 dilution) was then added at room temperature for $30 \mathrm{~min}$, followed by incubation with 
A

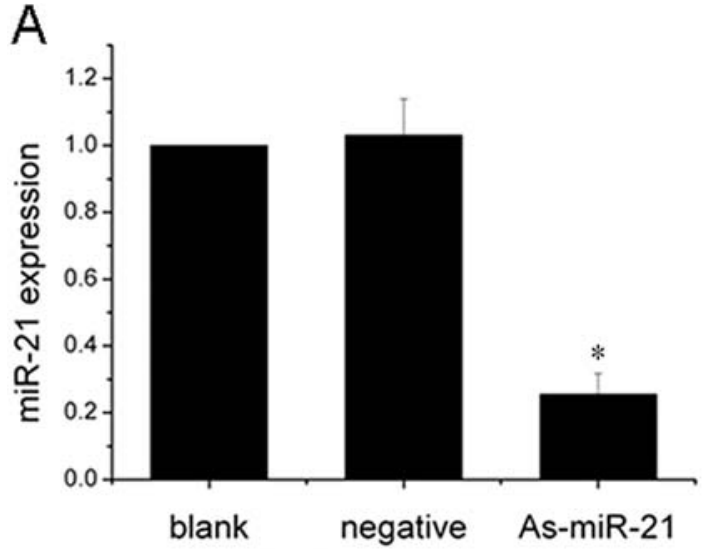

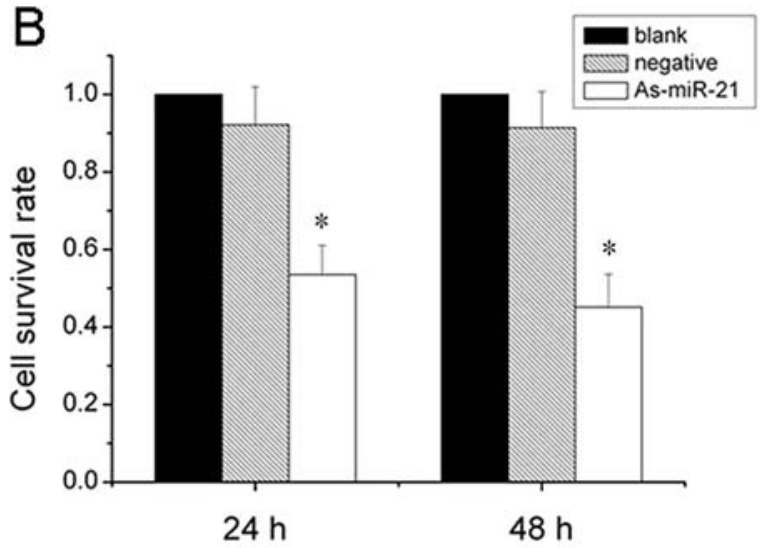

$24 \mathrm{~h}$

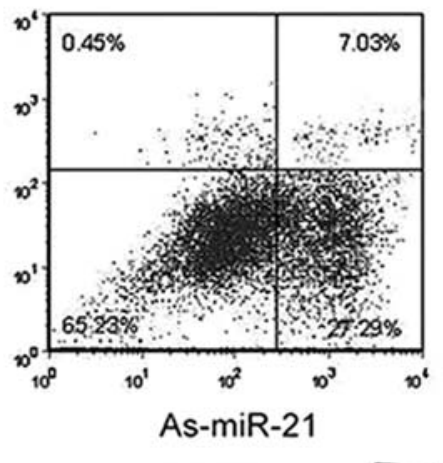

C
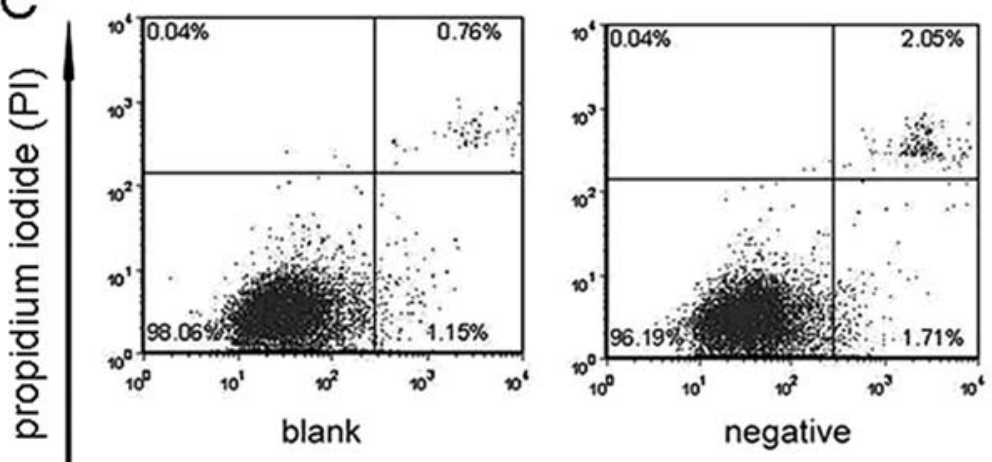

\section{Annexin V}

Figure 1. Reduction of miR-21 suppresses glioma cell proliferation and induces cell apoptosis. (A) As-miR-21 induced a marked decrease in miR-21 expression in U87 cells. (B) MTT assay showed that U87 treated with As-miR-21 proliferated at a significantly lower rate than control groups 24 and 48 h after transfection. (C) After $24 \mathrm{~h}$ treatment, cells were harvested and double stained for Annexin V and propidium iodide (PI) and analyzed by flow cytometry. Apoptotic cells are Annexin $\mathrm{V}^{+} / \mathrm{PI}^{-}$, necrotic cells are $\mathrm{V}^{+} / \mathrm{PI}^{-}$, and healthy cells are Annexin $\mathrm{V}^{-} / \mathrm{PI}^{-}$. A representative experiment of three performed is shown. ${ }^{*} \mathrm{P}<0.05$ compared with control groups.

ABC-peroxidase for an additional 30 min. After washing with Tris-buffer, the sections were incubated with DAB (3,3' diaminobenzidine, $30 \mathrm{mg}$ dissolved in $100 \mathrm{ml}$ Tris buffer containing $0.03 \% \mathrm{H}_{2} \mathrm{O}_{2}$ ) for $5 \mathrm{~min}$, rinsed in water and counterstained with hematoxylin.

Statistical analysis. Statistics was determined by ANOVA, or t-test using SPSS11.0. Statistical significance was determined as $\mathrm{P}<0.05$.

\section{Results}

As-miR-21 suppresses glioma cell proliferation and induced cell apoptosis. To evaluate the significance of miR-21 overexpression in glioma cells, a loss-of-function antisense approach was employed. An As-miR-21 oligonucleotide was used to knock down miR-21 expression in U87 cells. RT real-time PCR showed that the relative expression level of miR-21 in As-miR-21 group was $25.5 \%$ compared with control groups $(\mathrm{P}<0.05)$ (Fig. 1A). These data suggested that As-miR-21 potentially inhibited the endogenous miR-21 expression in U87 cells.

To study the biological function of As-miR-21 on cell proliferation of glioma cells, cell viability of U87 cells was measured by MTT assay. As shown in Fig. 1B, statistically significant cell proliferation of U87 cells was found in AsmiR-21 group compared with control groups 24 and $48 \mathrm{~h}$ after transfection. There was no difference between blank control group and negative control group in the whole experiment.

To further analyze whether decreased cell viability was a result of cell apoptosis, Annexin V and PI double staining were investigated. The Annexin V positive early phase apoptotic cells were significantly increased in cells transfected with AS-miR-21 (27.29\%) as compared to parental cells and cells transfected with scrambled oligonucleotides $(1.15 \%, 1.71 \%$, respectively) $(\mathrm{P}<0.05)$ (Fig. 1C).

As-miR-21 induces the activation of caspase 9 and 3. In order to determine the mechanism of miR-21 involved in glioma cell apoptosis, caspase pathways were tested. We determined caspase 3 activation after As-miR-21 transfection. As shown in Fig. 2A, $24 \mathrm{~h}$ after transfection, caspase 3 activation increased 3-fold in U87 cells treated with the As-miR-21 relative to mock-transfected cells or cells treated with the control oligonucleotides. Caspase 3 activation of $48 \mathrm{~h}$ after transfection was 2-fold higher than that of $24 \mathrm{~h}$ after transfection in As-miR-21 group. Different caspase pathways were involved in cell apoptosis, thus, the expression of caspase 9 was investigated by Western blotting. Reduction 

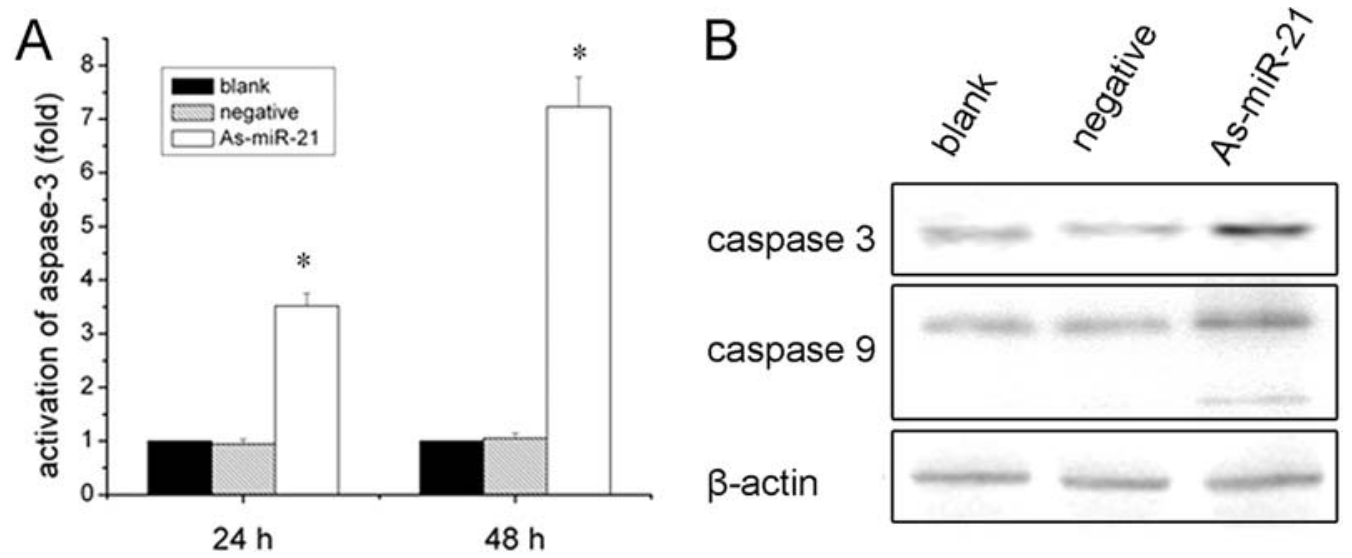

Figure 2. Reduction of miR-21 resulted in caspase 9 and 3 activation. (A) Caspase 3 activation after transfection with As-miR-21 by caspase 3 activity assay. (B) Suppression of miR-21 triggered the activation of caspase 9 and 3 by Western blotting. ${ }^{*} \mathrm{P}<0.05$ compared with control groups.

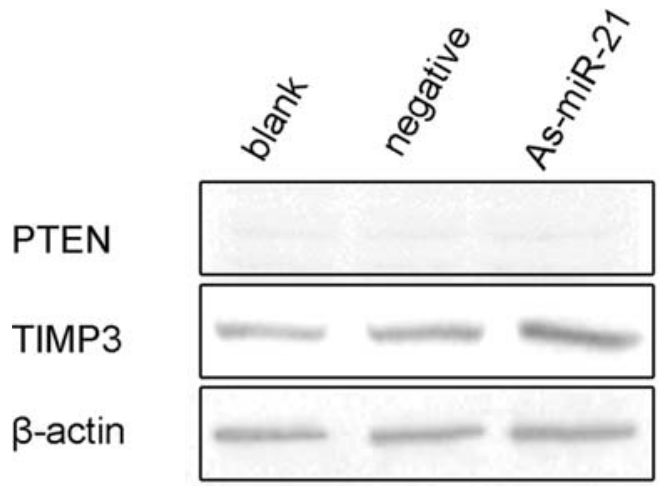

Figure 3. Expression of potential miR-21 target genes. U87 cells were transfected with As-miR-21, and the expression of TIMP3 and PTEN was analyzed by Western blotting. The expression of $B$-actin was used as a loading control.

of miR-21 resulted in a remarkable increase of activated caspase 9 (Fig. 2B). These results suggested that downregulation of miR-21 expression promoted glioma cell apoptosis via the caspase 9 and 3 pathway.

Expression of potential miR-21 target genes. To further explore the molecular mechanism of As-miR-21 induced cell apoptosis mediated by caspase 9 and 3, Western blot analysis was used. Since each target prediction program uses a different computer-aided algorithm for prediction, encompassing all these methods will probably produce a more reliable model of target prediction. Thus, using 3 target prediction programs (PicTar, TargetScan and miRanda), we obtained 82 target genes (data not show). Recently, several miR-21 direct target mRNAs, such as PDCD4, PTEN, RECK and TIMP3 $(6,8,12)$, were validated in different human cancer models. Some of the predicted and validated target genes, which probably participate in cell apoptosis, were analyzed. Reduction of miR-21 led to a marked increase of TIMP3 protein expression. There was no change of PTEN expression after reduction of miR-21 (Fig. 3).

As-miR-21 inhibits xenograft tumor growth in vivo. Given the in vitro data of glioma cells following treatment with
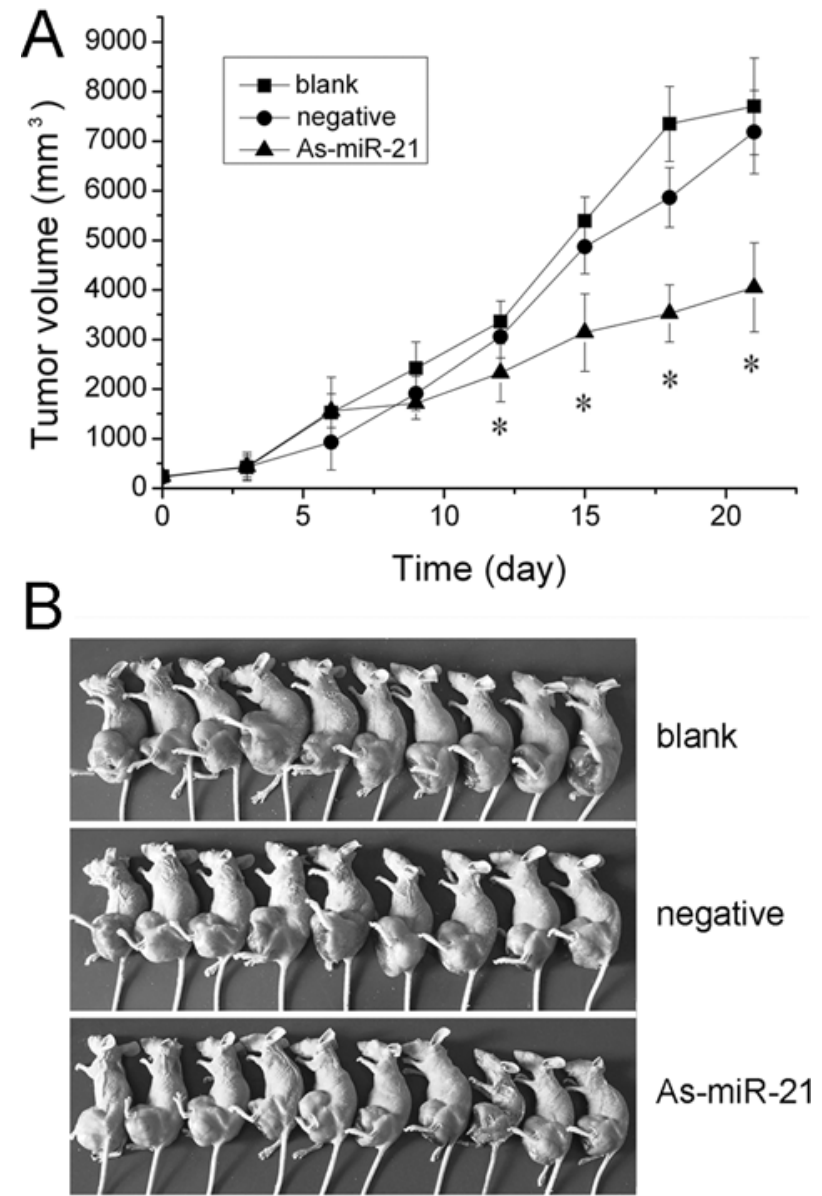

Figure 4. Reduction of miR-21 inhibites glioma growth in vivo. (A) When subcutaneous tumors were established, As-miR-21 was injected in a multisite injection manner. Tumor volumes were measured every 4 days during treatment. Down-regulation of miR-21 expression efficiently inhibited tumor growth in vivo. (B) The images show a representative animal from 3 groups at the end of the study. ${ }^{*} \mathrm{P}<0.05$ compared with control groups.

As-miR-21, next we evaluated the effect of As-miR-21 on tumor growth in a xenograft glioma mouse model. On day 12, tumors of As-miR-21 group started to reach statistical significance compared with control groups $(\mathrm{P}<0.05)$. At the termination of the study, the difference in tumor mass between 


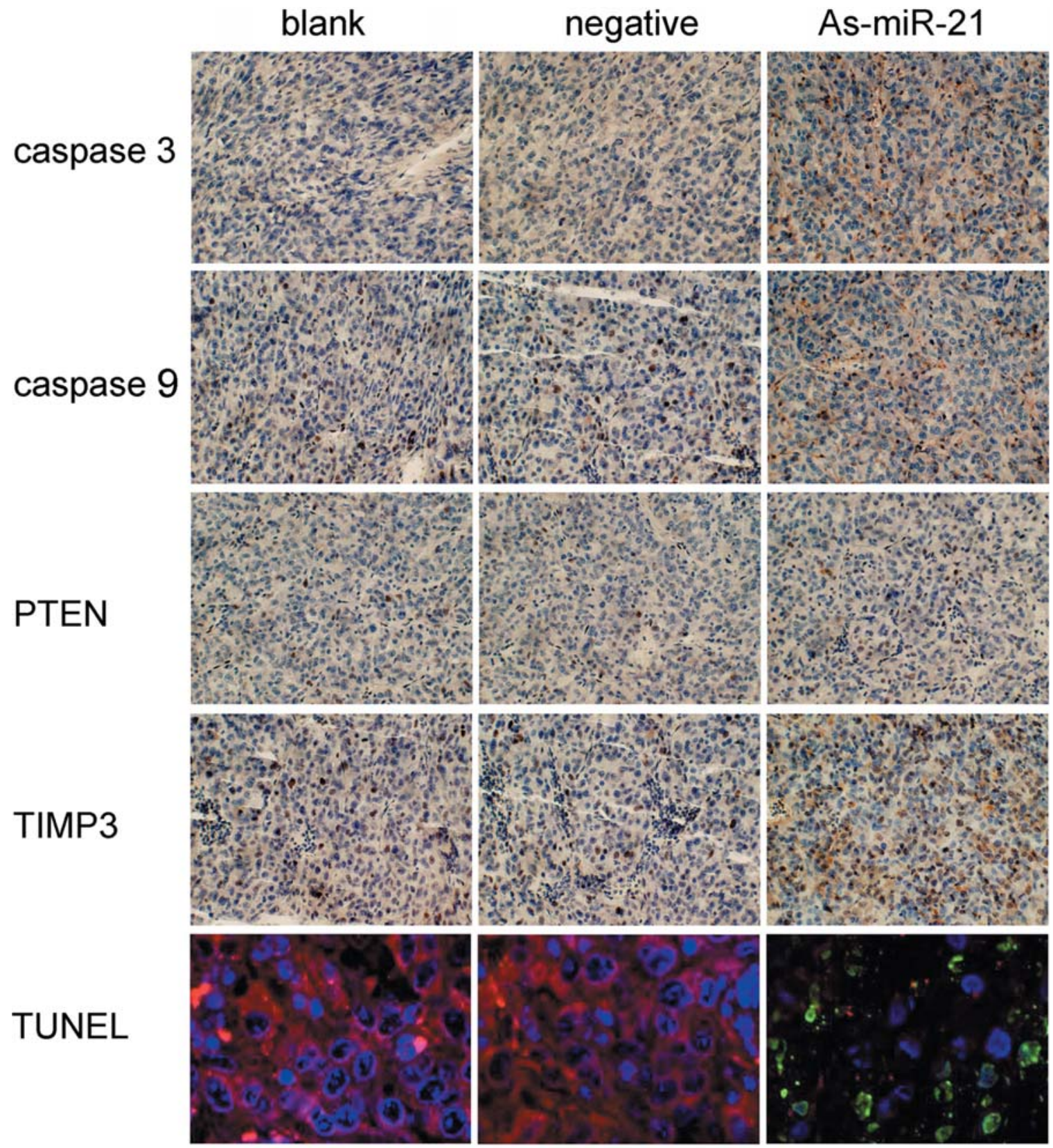

Figure 5. Immunohistochemistry analyses of xenograft tumors after As-miR-21 treatment. MiR-21 expression was significantly decreased and abundant apoptotic nuclei were observed in U87 xenograft tumors of AS-miR-21 group by in situ hybridization and TUNEL assay. Additionally, the expression level of caspase 3 and TIMP3 was up-regulated in the tumors of AS-miR-21 group.

As-miR-21 group and control groups was marked $(\mathrm{P}<0.01)$. As shown in Fig. 4, the average tumor volumes on day 21 were 7970.2, 7179.9 and $4209.1 \mathrm{~mm}^{3}$ in blank control group, negative control group and As-miR-21 group, respectively.

Next, we detected miR-21 expression by in situ hybridization and apoptosis by TUNEL assay. In the As-miR-21 treated xenograft tumors, miR-21 expression was markedly decreased and abundant apoptotic nuclei were observed. In contrast, miR-21 was highly expressed in the tumors of control groups, no apoptotic nuclei were found. In order to verify the data of the gene expression level induced by AsmiR-21 in vitro, we determined the protein expression of these genes by immunohistochemistry. Similar effects on caspase 3, caspase 9, TIMP3 and PTEN were achieved in
As-miR-21 group, in line with the in vitro experiments. Representative photomicrographs are shown in Fig. 5.

\section{Discussion}

Since miRNAs can function as tumor suppressors and oncogenes, miRNA abnormalities are thought to be widely involved in tumorigenesis. Recent evidence indicates that miR-21 participate in development and progression of human tumors, such as glioblastoma, hepatocellular, lung, colon, and prostate cancer $(8,12-15)$. In this study, down-regulation of miR-21 by As-miR-21 resulted in inhibition of cell proliferation and apoptosis induction in U87 glioma cells. Further, As-miR-21 regulated multiple potential target genes 
and then activated the caspase 9 and 3 pathway. In our in vivo study, As-miR-21 led to apoptosis-mediated tumor growth inhibtion in a xenograft tumor mouse model, confirming the experiment in vitro.

Apoptosis can be initiated by three different pathways: i) the extrinsic pathway, which can be induced by ligation of death receptors and subsequent caspase 8 activation; ii) the intrinsic or mitochondrial pathway, which is triggered by cellular stress followed by activation of caspase 9; iii) the granzyme B pathway, where the cytotoxic cell protease granzyme B is delivered to sensitive target cells. Each of these three pathways converges to a same execution phase of apoptosis that requires activation of caspases 3 and/or 7 $(16,17)$. In extrinsic apoptotic pathway, typical death receptors are fibroblast associated antigen (FAS, also called CD95) and tumor necrosis factor receptor (TNFR). Ligation of death receptor causes formation of death inducing signaling complex (DISC), and results in the recruitment of caspase 8 or 10 to the DISC (18). The activated caspase then proteolytically activates downstream effector caspases. Unlike the death receptor-dependent pathway, the mitochondria-dependent pathway is mediated by translocation of BAX and BAK to the mitochondrial membrane, subsequent release of cytochrome c from mitochondria (19).

Anti-apoptotic BCL2 family members, prevent cytochrome $\mathrm{c}$ release, by binding and inhibition of $\mathrm{BAX}$ and BAK. Cytochrome c subsequently binds to the Apaf1 and causes recruitment of pro-caspase 9 to the complex (20). Activated caspase 9 in turn activates caspase 3 and initiates the proteolytic cascade (21). Of note, a previous study by Chan et al reported that knockdown of miR-21 by antisense oligonucleotides in cultured glioblastoma cells can trigger activation of caspase 3 and 7 and lead to increased apoptotic cell death (22). However, the data did not elucidate which apoptotic pathway mediated cell apoptosis induced by AsmiR-21. Herein, our results found that an obvious activation of caspase 9 and 3 in glioma cells was observed after AsmiR-21 transfection, suggesting that reduction of miR-21 can promote glioma cell apoptosis via the caspase 9 and 3 mediated intrinsic pathway.

The further mechanism involved in caspase 9 and 3 signalling pathway regulated by miR-21 is not clear and still under investigation. Each miRNA has the potential to regulate 200 target genes according to recent computational predictions. Therefore, we used bioinformatics to clarify the common targets of miR-21 by 3 computer predictions. Data suggested that miR-21 has the potential to regulate $\sim 82$ common target genes. Recently, PDCD4, PTEN, RECK and TIMP3, have been successfully identified as direct targets of miR-21, and contribute to the control of cancer cell proliferation, apoptosis and invasion. PDCD4, an important tumor suppressor gene in cell apoptosis, experimentally proved to be miR-21 target in MCF-7 breast cancer cells and T98G glioma cells $(8,23)$. PTEN tumor suppressor mRNA 3' UTR contains miR-21 binding sequence and its translation process was suppressed by miR-21 molecule in hepatocellular carcinoma (12). In addition, miR-21 inhibited RECK and TIMP3 genes to mediate A172 glioma cell, Hela cervical carcinoma cell and MCF-7 cell invasion ability (6). In our study, down-regulation of miR-21 expression induced a marked increase of TIMP3 protein expression, without any change of PTEN expression. This may be explained by the loss of PTEN in U87 glioma cells. Our result indicated that miR-21 may regulate these potential targets to activate the caspase 9 and 3 pathway. In prostate cancer cells, overexpression of TIMP3 induced apoptotic cell death triggered by mitochondrion-mediated caspase 3 activation and greatly sensitized prostate cancer cells to chemotherapeutic drug paclitaxel (24).

In summary, we showed that reduction of miR-21 by antisense oligonucleotides can activate caspase 9 and 3 pathway possibly mediated by multiple potential target genes, and subsequently induce glioma cell apoptosis. These results suggest that modulation of the mechanism responsible for miR-21 in glioma could be used as a therapeutic strategy for glioma treatment and warrants further investigation.

\section{Acknowledgments}

This study was supported by the China Natural Science Foundation (30872657 and 30971136), Program for New Century Excellent Talents in University (NCET-07-0615), Natural Science Foundation of Tianjin Municipal Science and Technology Commission (09JZCDJC17600), and Medical Major Talent Program of Jiangsu Province (RC2007061).

\section{References}

1. Yanaihara N, Caplen N, Bowman E, Seike M, Kumamoto K, Yi M, Stephens RM, Okamoto A, Yokota J, Tanaka T, Calin GA, Liu CG, Croce CM and Harris CC: Unique microRNA molecular profiles in lung cancer diagnosis and prognosis. Cancer Cell 9: 189-198, 2006.

2. Shi L, Cheng Z, Zhang J, Li R, Zhao P, Fu Z and You Y: hsamir-181a and hsa-mir-181b function as tumor suppressors in human glioma cells. Brain Res 1236: 185-193, 2008.

3. Calin GA and Croce CM: MicroRNA signatures in human cancers. Nat Rev Cancer 6: 857-866, 2006.

4. Ciafre SA, Galardi S, Mangiola A, Ferracin M, Liu CG, Sabatino G, Negrini M, Maira G, Croce CM and Farace MG: Extensive modulation of a set of microRNAs in primary glioblastoma. Biochem Biophys Res Commun 334: 1351-1358, 2005.

5. Zhou X, Ren Y, Moore L, Mei M, You Y, Xu P, Wang B, Wang G, Jia Z, Pu P, Zhang W and Kang C: Downregulation of miR-21 inhibits EGFR pathway and suppresses the growth of human glioblastoma cells independent of PTEN status. Lab Invest 90: 144-155, 2010.

6. Gabriely G, Wurdinger T, Kesari S, Esau CC, Burchard J, Linsley PS and Krichevsky AM: MicroRNA 21 promotes glioma invasion by targeting matrix metalloproteinase regulators. Mol Cell Biol 28: 5369-5380, 2008.

7. Li Y, Li W, Yang Y, Lu Y, He C, Hu G, Liu H, Chen J, He J and $\mathrm{Yu} \mathrm{H}$ : MicroRNA-21 targets LRRFIP1 and contributes to VM-26 resistance in glioblastoma multiforme. Brain Res 1286: 13-18, 2009.

8. Chen Y, Liu W, Chao T, Zhang Y, Yan X, Gong Y, Qiang B, Yuan J, Sun M and Peng X: MicroRNA-21 down-regulates the expression of tumor suppressor PDCD4 in human glioblastoma cell T98G. Cancer Lett 272: 197-205, 2008.

9. Zhou X, Ren Y, Han L, Mei M, Xu P, Zhang CZ, Wang GX, Jia ZF, Pu PY and Kang CS: Role of the AKT pathway in microRNA expression of human U251 glioblastoma cells. Int J Oncol 36: 665-672, 2010.

10. Zhao P, Wang C, Fu Z, You Y, Cheng Y, Lu X, Lu A, Liu N, $\mathrm{Pu}$ P, Kang C, Salford L G and Fan X: Lentiviral vector mediated siRNA knock-down of hTERT results in diminished capacity in invasiveness and in vivo growth of human glioma cells in a telomere length-independent manner. Int J Oncol 31: 361-368, 2007. 
11. You Y, Geng X, Zhao P, Fu Z, Wang C, Chao S, Liu N, Lu A, Gardner K, Pu P, Kong C, Ge Y, Judge SI and Li QQ: Evaluation of combination gene therapy with PTEN and antisense hTERT for malignant glioma in vitro and xenografts. Cell Mol Life Sci 64: 621-631, 2007.

12. Meng F, Henson R, Wehbe-Janek H, Ghoshal K, Jacob ST and Patel T: MicroRNA-21 regulates expression of the PTEN tumor suppressor gene in human hepatocellular cancer. Gastroenterology 133: 647-658, 2007.

13. Seike M, Goto A, Okano T, Bowman ED, Schetter AJ, Horikawa I, Mathe EA, Jen J, Yang P, Sugimura H, Gemma A, Kudoh S, Croce CM and Harris CC: MiR-21 is an EGFRregulated anti-apoptotic factor in lung cancer in never-smokers. Proc Natl Acad Sci USA 106: 12085-12090, 2009.

14. Wang P, Zou F, Zhang X, Li H, Dulak A, Tomko RJ Jr, Lazo JS, Wang Z, Zhang $L$ and Yu J: microRNA-21 negatively regulates $\mathrm{Cdc} 25 \mathrm{~A}$ and cell cycle progression in colon cancer cells. Cancer Res 69: 8157-8165, 2009.

15. Ribas J, Ni X, Haffner M, Wentzel EA, Salmasi AH, Chowdhury WH, Kudrolli TA, Yegnasubramanian S, Luo J, Rodriguez R, Mendell JT and Lupold SE: miR-21: an androgen receptor-regulated microRNA that promotes hormone-dependent and hormone-independent prostate cancer growth. Cancer Res 69: 7165-7169, 2009.

16. Ghavami S, Hashemi M, Ande SR, Yeganeh B, Xiao W, Eshraghi M, Bus CJ, Kadkhoda K, Wiechec E, Halayko AJ and Los M: Apoptosis and cancer: mutations within caspase genes. J Med Genet 46: 497-510, 2009.
17. Salvesen GS and Dixit VM: Caspases: intracellular signaling by proteolysis. Cell 91: 443-446, 1997.

18. Bodmer JL, Holler N, Reynard S, Vinciguerra P, Schneider P, Juo P, Blenis J and Tschopp J: TRAIL receptor-2 signals apoptosis through FADD and caspase-8. Nat Cell Biol 2: 241-243, 2000.

19. Kim R: Recent advances in understanding the cell death pathways activated by anticancer therapy. Cancer 103: 1551-1560, 2005.

20. Ghobrial IM, Witzig TE and Adjei AA: Targeting apoptosis pathways in cancer therapy. CA Cancer J Clin 55: 178-194, 2005.

21. Li P, Nijhawan D, Budihardjo I, Srinivasula SM, Ahmad M, Alnemri ES and Wang X: Cytochrome c and dATP-dependent formation of Apaf-1/caspase-9 complex initiates an apoptotic protease cascade. Cell 91: 479-489, 1997.

22. Chan JA, Krichevsky AM and Kosik KS: MicroRNA-21 is an antiapoptotic factor in human glioblastoma cells. Cancer Res 65: 6029-6033, 2005

23. Lu Z, Liu M, Stribinskis V, Klinge CM, Ramos KS, Colburn NH and Li Y: MicroRNA-21 promotes cell transformation by targeting the programmed cell death 4 gene. Oncogene 27: 4373-4379, 2008.

24. Deng X, Bhagat S, Dong Z, Mullins C, Chinni SR and Cher M: Tissue inhibitor of metalloproteinase-3 induces apoptosis in prostate cancer cells and confers increased sensitivity to paclitaxel. Eur J Cancer 42: 3267-3273, 2006. 